\title{
Extraction of Jatropha Bio-base Oil for Two-Stroke Engines
}

\author{
Hunaida Abd Elbage Abazar Ahmed, Kamal Eldin Eltayeb Yassin \\ Chemical Engineering Department, \\ University of Khartoum, Sudan
}

\begin{abstract}
Bio-lubricant based oil was developed from Jatropha oil; it is considered the best alternative to traditional lubricants based on mineral oils and synthesis esters. This study intended ameliorating the environmental control measures of air pollutants by preparing base oil from local ingredients for two-stroke engines lubrication in Sudan. American Society for Testing and Materials has applied for analyzing the physiochemical characteristics of oil based on Jatropha. Based on the experiment conducted, we found that oil based on Jatropha as bio-lubricant has high flash point $\left(266^{\circ} \mathrm{C}\right)$, viscosity index (354),American Petroleum Institute of 17 , an acid number of $0.457 \mathrm{mg} \mathrm{KOH} / \mathrm{mg}$, carbon residue $(0.001 \mathrm{w} / \mathrm{w} \%)$, and low pour point of $-13{ }^{\circ} \mathrm{C}$. By comparing the obtained results with those of commercially used oils for two-stroke engines, the proposed alternative is far better in its quality and it meets the minimum requirements of international and local standards. Finally, it was recommended to use oil based on Jatropha oil for two-stroke engines to improve the environmental conditions by mitigating emissions from point sources. In addition, more research is needed to study future production and its quantities for the manufacture of bio-lubricants from local ingredients. One day, lubricants based on mineral oils will replaced with biologically based products in environmentally sensitive applications.
\end{abstract}

Keywords: Jatropha oil, Bio-lubricant, Two-stroke engines, Trans-esterification, Aryl-alkylation

\section{INTRODUCTION}

Two-stroke engines are considered total-loss type lubricating systems therefore the oil is mixed with fuel [1]. Emissions from 2stroke engines can be reduced by rigorous inspection and maintenance programs and used of lubricating oil of correct quality and quantity $[2,3,4]$. Bio-lubricant oils are perceived as alternatives to mineral oils because they possess certain natural technical properties and they are biodegradable $[5,6]$.

Jatropha is small evergreen tree and grows in the wildness [7]. The oil is not fit for human consumption or animals therefore it could be used to produce bio-fuel that burns without hazardous emissions to the environment [8].

\section{MATERIALS AND METHODS}

\section{$2.1 \quad$ Materials}

Jatropha seeds were acquired from National Center for Agricultural and Forests Researches. Jatropha oil was extracted mechanically using cold pressing method to avoid water added during extraction process. It was analyzed for free fatty composition using gas chromatography analyzer in the central laboratory at Khartoum University (Table 2-1). Bio-lubricant base oil is extracted from Jatropha oil using acetic anhydride, 2-Ethyl-1- hexanol, sodium, Toluene, aluminum chloride and hydrochloric acid.

Table 2-1: Fatty acid composition of Jatropha oil

\begin{tabular}{|l|l|l|}
\hline \multicolumn{2}{|l|}{ Fatty acid } & \multicolumn{1}{c|}{ Composition \% } \\
\hline \multirow{5}{*}{ Unsaturated } & Palmitoleic (C16:1) & 0.8 \\
\cline { 2 - 3 } & cis-10-Heptadcanoic (C17:1) & 0.2 \\
\cline { 2 - 3 } & Oleic (C18:1) & 36.5 \\
\cline { 2 - 3 } & Linoleic (C18:2) & 41.3 \\
\cline { 2 - 3 } & cis-11-Eicosenoic (C20:1) & 0.2 \\
\cline { 2 - 3 } & cis-13,16-Docosadienoic (C22:2) & 0.8 \\
\hline \multirow{5}{*}{ Saturated } & Palmitic (C16:0) & 10.0 \\
\cline { 2 - 3 } & Heptadcanoic (C17:0) & 0.1 \\
\cline { 2 - 3 } & Stearic (C18:0) & 8.8 \\
\cline { 2 - 3 } & Tricosanoic (C23:0) & 1.3 \\
\hline
\end{tabular}

\subsection{Preparation of base oil}

\subsubsection{Acetylation}

Acetylation was needed to provide the hydrocarbon solubility of Jatropha oil [9]. 250g of Jatropha oil was reacted with 80g of acetic anhydride under constant stirring. Acetic anhydride was added dropwise during a period of 45 min at $40-50^{\circ} \mathrm{C}$. Then, the temperature was slowly raised to $120^{\circ} \mathrm{C}$ during the next $160 \mathrm{~min}$ while the contents were stirred constantly. The mixture was washed with distilled water from excess acetic anhydride until pH 6-7 (Figure 2-1). 
$230 \mathrm{~g}$ of acetylated Jatropha oil was mixed with $57.5 \mathrm{~g}$ of toluene $\left(25 \%\right.$ of acetylated $\mathrm{J}$. oil) and heated to $70^{\circ} \mathrm{C}$, then the mixture was heated under vacuum $\left(-0.6 \mathrm{bar}, 66^{\circ} \mathrm{C}\right)$ in vacuum pan connected with distillation column to separate the water and toluene.

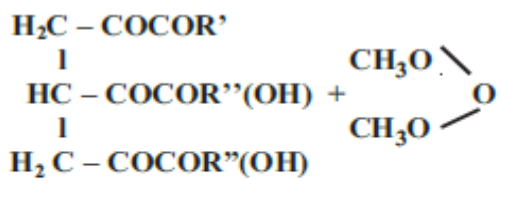

Jatropha oil triglyceride Acetic anhydrie

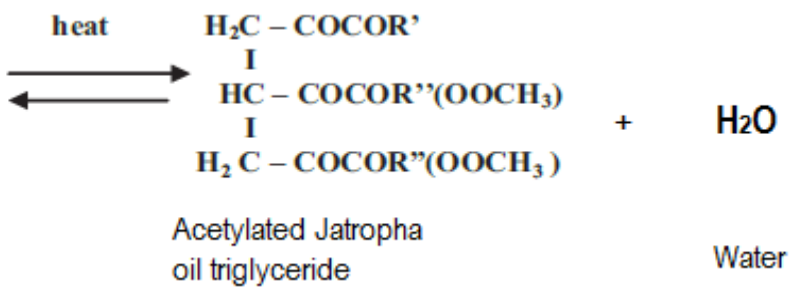

Figure 2-1: Acetylation of Jatropha oil

\subsubsection{Trans-esterification}

$200 \mathrm{~g}$ of 2-ethyl-1-hexanol was heated with $1 \mathrm{~g}$ of sodium in magnetic heater with constant stirring. The temperature of mixture was slowly raised until all sodium dissolved to give clear solution at $90^{\circ} \mathrm{C}$. This sodium ethyl hexanoate was added to $218 \mathrm{~g}$ of acetylated Jatropha oil in magnetic heater at $80-110^{\circ} \mathrm{C}$ with continuous stirring. Then the temperature of reaction was raised to $163-172^{\circ} \mathrm{C}$ for $22 \mathrm{hrs}$. (Figure 2-2) [10,6].

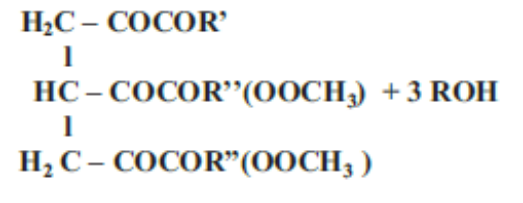

Acetylated triglyceride $\quad$ 2-ethyl-1-hexanol

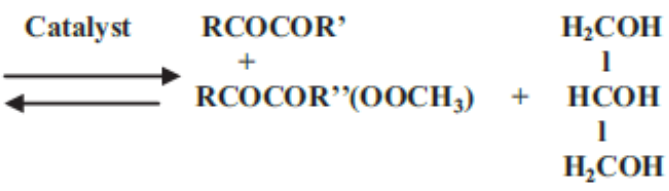

mix of mono ester

Glycerol

Figure 2-2: Trans-esterification of Jatropha oil

Steam with 1.2 bar and $100^{\circ} \mathrm{C}$ was passed through the mixture until sodium ethyl hexanoate hydrolyzed. After $20 \mathrm{hrs}$ at room temperature, two layers were totally separated that were glycerol and ester. The ester was dissolved in toluene to remove the traces of water in vacuum pan at $66^{\circ} \mathrm{C}$ and -0.6 bar.

\subsubsection{Aryl-alkylation}

$174 \mathrm{~g}$ of ester was dissolved in $430 \mathrm{~g}$ of toluene and cooled to $-11^{\circ} \mathrm{C}$ in a freezer. $10 \mathrm{~g}$ of $\mathrm{AlCl}_{3}$ was slowly added over a period of $55 \mathrm{~min}$. During the addition, the temperature was allowed to rise to $3^{\circ} \mathrm{C}$ and the reaction mixture was maintained at $0^{\circ} \mathrm{C}$ for 12 and half hrs. with constant stirring. After that, the contents were poured into water with $10 \%$ hydrochloric acid and kept for 9 hrs. The upper layer was washed rapidly to remove the acidity. Then the upper layer was heated under vacuum $\left(66^{\circ} \mathrm{C}\right.$ and -0.6 bar) in vacuum pan to remove the washed water and the excess of toluene. The product was tolyl ethyl hexyl ester of Jatropha fatty acid (herein referred to JT) (Figure 2-3).

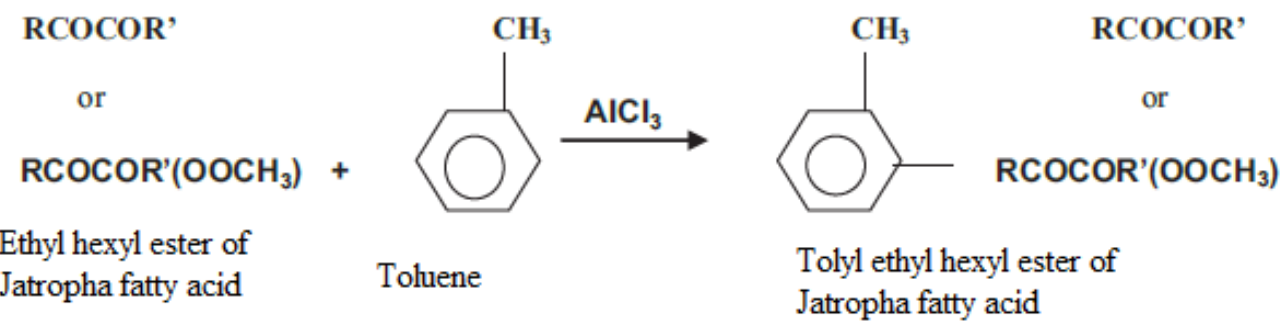

Figure 2-3: Alkylation of Ethyl hexyl ester of Jatropha oil fatty acid

\subsection{Characterization of the base oil: laboratory analysis}

For characterization of JT oil, standard methods were used that were given in Table 2-2 and the experimental values are reported in 
Table 3-2. All tests were conducted in the professional laboratories of faculty of Engineering, Khartoum University.

Table 2-2: Standard methods used for JT oil analysis

\begin{tabular}{|l|l|}
\hline Analysis & Methods \\
\hline Kinematic viscosity & ASTM D445 \\
\hline Viscosity index & ASTM D2270 \\
\hline Density & ASTM D4052 \\
\hline API gravity & ASTM for density, relative density or API gravity of crude oil. \\
\hline Pour point & ASTM D97 \\
\hline Flash point by Cleveland open cup & ASTM D92 \\
\hline Carbon residue & ASTM D4530 \\
\hline Water content & ASTM D6304 \\
\hline Copper corrosion & ASTM D130 \\
\hline Acid number and strong acid & ASTM D644 \\
\hline
\end{tabular}

\section{RESULTS AND DISCUSSION}

\subsection{Materials balance}

In this study, lubricant based oil was prepared from Jatropha oil through three phases had been discussed in 2.2). The amount of chemicals that are required for those reactions had been calculated based on the stoichiometric equations Figure 2-1, Figure 2-2 and Figure 2-3 and was shown in Table 3-1.

Table 3-1: The amount of chemicals was reacted to prepare JT oil

\begin{tabular}{|c|c|c|c|c|}
\hline \multicolumn{2}{|r|}{ The material } & $\begin{array}{l}\text { Mole required for } \\
\text { reaction }\end{array}$ & $\begin{array}{c}\text { Stoichiometric mass } \\
\text { (g) }\end{array}$ & Amount reacted $(\mathrm{g})$ \\
\hline \multicolumn{2}{|c|}{ Jatropha oil } & 1 & 827.59 & 250 \\
\hline \multicolumn{2}{|c|}{ Acetic anhydride } & 1 & 102.09 & 80 \\
\hline \multicolumn{2}{|c|}{ Acetylated J. triglyceride } & 1 & 911.68 & 218.19 \\
\hline \multicolumn{2}{|c|}{ 2-Ethyl-1-hexanol } & 3 & 390.69 & 200 \\
\hline \multicolumn{2}{|c|}{ Ethyl hexyl ester of J. fatty acid } & 1 & 1210.28 & 174 \\
\hline \multicolumn{2}{|c|}{ Toluene } & 1 & 92.14 & 430 \\
\hline \multirow{2}{*}{ Catalyst } & Sodium & - & - & 1 \\
\hline & Aluminum chloride & - & - & 10 \\
\hline
\end{tabular}

\subsection{Physio-chemical characteristics of JT oil}

Jatropha oil is high rich in oleic oil (C18:1) and Linoleic (C18:2), having around 77\% of C18:1 and C18:2 (Table 2-1). Oleic is considered more stable than other un-saturated fatty acids [11]. However, hydroxyl group makes it insoluble in gasoline. Pour point and viscosity index below 95 also was not desirable therefore; raw Jatropha oil could not be used for $2 T$ oil as such. Flash point was suitable for its application as lubricants. Considering all properties, it was needed to be converted to aryl-alkylated ethyl-hexyl ester [12]. After the conversion, its viscosity index of 354 (

Table 3-2) was met the minimum requirement of 90 and kinematic viscosities at $100^{\circ} \mathrm{C}$ was $26.12 \mathrm{cSt}$. JT oil had a flash point of above $250^{\circ} \mathrm{C}$ as measured, which it is considered safe product for storage and transportation. Pour point of it was $-13^{\circ} \mathrm{C}$ as determined that means there is no trouble to use in Sudan during summer and winter without the addition of polymer or pour point depressant as due to metrological conditions of Sudan.

For Copper strip corrosion, JT oil was classified as 1a after the copper strip was heated at $120^{\circ} \mathrm{C}$ for $3 \mathrm{hrs}$. according to ASTM D130, which is met the minimum requirement of standard. The TAN- should not be more than $0.5 \mathrm{mg} \mathrm{KOH} / \mathrm{g}$ as is prescribed by standard specifications for petroleum turbine lubricating oil's stability, which was possible due to chemical modification of Jatropha oil (

Table 3-2). Fatty acid monoesters are more stable than vegetable oils.

The developed base-stock (JT oil) of two-stroke engines from Jatropha oil was in conformity with specifications, which was a significant achievement. 
Table 3-2: Physio-chemical characteristics of JT oil

\begin{tabular}{|c|c|c|c|}
\hline Characteristic & Method of test & Actual specification & Targeted specs. \\
\hline Density @ 30 $\mathrm{C}(\mathrm{g} / \mathrm{ml})$ & ASTM D4052 & 0.943 & To be reported \\
\hline Density @ $15^{\circ} \mathrm{C}(\mathrm{g} / \mathrm{ml})$ & ASTM D4052 & 0.953 & To be reported \\
\hline API & - & 17.0 & $>10$ \\
\hline Kinematic viscosity @ $40^{\circ} \mathrm{C}(\mathrm{cSt})$ & ASTM D445 & 79.06 & $45 \mathrm{~min}$ \\
\hline Kinematic viscosity @ $100^{\circ} \mathrm{C}(\mathrm{cSt})$ & ASTM D445 & 26.12 & $6.5 \mathrm{~min}$ \\
\hline Viscosity index & ASTM D2270 & 354 & $90 \mathrm{~min}$ \\
\hline Flash point $\left({ }^{\circ} \mathrm{C}\right)$ & ASTM D92 & 266 & $70 \mathrm{~min}$ \\
\hline Pour point $\left({ }^{\circ} \mathrm{C}\right)$ & ASTM D97 & -13 & $-6 \max$ \\
\hline Carbon residue (w/w \%) & ASTM D4530 & 0.001 & $0.6 \max$ \\
\hline Water content (vol. \%) & ASTM D6304 & 0 & $0.03 \max$ \\
\hline Copper strip corrosion $\left(3 \mathrm{~h} / 120^{\circ} \mathrm{C}\right)$ & ASTM D130 & $1 \mathrm{a}$ & $1 \max$ \\
\hline Total acid number (mg KOH/g) & ASTM D664 & 0.457 & $0.5 \max$ \\
\hline Strong acid number & ASTM D664 & Nil & Nil \\
\hline
\end{tabular}

\section{CONCULUSION}

The bush "Jatropha" represents the most important trees, on which interest began to a large extent, within the framework of a new concept called the project of cultivating energy that can be an alternative to mineral oils, petroleum based oils and petroleumderived fuel.

In response to reducing the amount of air pollutants, automobile fuels and lubricants offer the most plausible solution to obtaining renewable and eco-friendly lubricants. Renewable, biodegradable and environmentally friendly base oil was prepared from local an ingredient that is Jatropha oil. Jatropha based oil has high flash point $\left(266^{\circ} \mathrm{C}\right)$, viscosity index $(354)$, carbon residue $(0.001 \mathrm{wt} \%)$, an acid value of $0.457 \mathrm{mg} \mathrm{KOH} / \mathrm{g}$, density @ $15^{\circ} \mathrm{C}$ of $0.953 \mathrm{~g} / \mathrm{ml}$ and low pour point of $-13^{\circ} \mathrm{C}$. Jatropha based oil is more viscous than the standard engine super $20 \mathrm{w} / 50$ and has lower acid values than the mineral lubricant, which makes it of higher yield or quality.

\section{REFERENCES}

[1] AMSOIL, "Two-cycle Engine Applications and Lubrication Needs," AMSOIL Action News, July 2001.

[2] K. E. Yassin, Pollution by 2-Stroke Engines, Khartoum: Sudanese Standard and Metrology Organization, 2017.

[3] M. Islam, "STRATEGIES TO PHASE OUT LEADED GASOLINE AND TWO STROKE ENGINES IN BANGLADESH: TECHNICAL, ECONOMIC, AND PUBLIC HEALTH CONSIDERATIONS.," Environmental Protection Agency, US, 1999.

[4] Jsong, "Emission Control of Two- and Three-Wheel Vehicles," Manufacturers of Emission Controls Association, 2014.

[5] A. K. Jain and A. Suhane, "Capability of Bio-lubricants as alternative Lubricant in Industrial and Maintenace Applications," International Journal of Current Engineering and Technology, vol. 3, no. 2277- 4106, pp. 179-183, 2013.

[6] P. S. Chauhan and V. K. Chhibber, "Non-Edible Oil as a Source of Bio-Lubricant for Industrial Applications," International Journal of Engineering Science and Innovative Technology (IJESIT), vol. 2, no. 1, pp. 299-305, January 2013.

[7] R. Misra and M. Murthy, "Jatropha the future fuel of india," Renewable and Sustainable Energy Reviews, vol. 15, pp. 1350-1359, 2011.

[8] A. Alhaj, "Jatropha tree to help produce fuel," Sudan Now Magazine, Khartoum, 2011.

[9] G. O and F. H, "Acetylated castor oil," Ind. Eng. Chem, vol. 37, no. 5, pp. 485-491, 1945.

[10] C. Y. May, "Transesterification of Palm Oil: effect of reaction parameters," Oil Palm Research, vol. 16, no. 2, pp. 1-11, 2004.

[11] E. S.Z., S. B.K. and P. J.M., "Oxidation and low temperature stability of vegetable oil-based lubricants," Ind. Crop. Prod., vol. 24, pp. 292-299, 2006.

[12] S. A.K., "Mono-ester of high viscosity from vegetable oils," in 10th lubricating Grease Conference Proceeding (NLGI), Aurangabad, 2008. 